\title{
К ВОПРОСУ О СОСТАВЕ ГУМИНОВЫХ КИСЛОТ ТОРФОВ СИБИРИ
}

\author{
() Л.И. Инишева ${ }^{1 *}$, С.Г. Маслов \\ ${ }^{1}$ Томский государственный педагогический университет, ул. Киевская, 60, \\ Томск, 634061 (Россия), e-mail: inisheva@mail.ru \\ ${ }^{2}$ Институт природных ресурсов Томского политехнического университета, \\ ул. Ленина, 30, Томск, 634050 (Россия), e-mail: maslovSG@tpu.ru
}

\begin{abstract}
Одним из источников природного сырья для получения экологически чистой продукции является торф. Немаловажно также, что исследования состава органического вещества $(\mathrm{OB})$ торфов с учетом ботанического состава малочисленны, выполнены с использованием разных методов анализа и не всегда могут быть сравнимы. Поэтому целью данной работы было изучение фракционно-группового состава ОВ торфов разного генезиса.

В пределах таежной и подтаежной областей отобрано 140 образцов торфов. Каждый вид торфа по ботаническому составу представлен выборкой из 6-19 образцов. Проведен анализ состава органического вещества торфов по методу В.В. Пономаревой и Т.А. Николаевой, что позволило более подробно охарактеризовать фракции гуминовых кислот. Так, общее содержание ГК в торфах низинного типа возрастает в ряду травяно-моховая группа - моховая группа - древесная группа - древесно-травяная, травяная группа. По содержанию ГК1 торфа одноименных ботанических групп разных типов торфа различаются в меньшей степени, чем торфа разного ботанического состава одного типа. Получено, что геохимические условия торфообразования оказывают влияние на содержание ГК2 в торфах. Во всех исследуемых торфах в составе ГК преобладает ГК 3 . Она составляет около $60 \%$ от суммы ГК и определяет основные закономерности изменений в общем содержании ГК.
\end{abstract}

Ключевые слова: торф, Западная Сибирь, органическое вещество, гуминовые кислоты, зольность, торфообразование.

Работа выполнена при частичной финансовой поддержке Минобрнауки (госзадание ТГПУ №174).

\section{Введение}

За последнее время интерес к изучению гуминовых кислот торфов существенно возрос [1-3], что связано с возможностью получения продукции на основе торфа.

Как правило, исследователи берут несколько видов торфа, а часто - только один, при этом не привязывая его к пункту отбора, не определяя сырьевую базу торфов для будущей продукции, и проводят углубленное изучение химических свойств, а в случае их использования в медицине - еще и дорогостоящие фармакологические исследования. Однако состав и свойства торфов изменяются в широких пределах, что определяется многообразием растений-торфообразователей, уровнем распада органического вещества и условиями торфонакопления. Поэтому полученные результаты, как правило, нельзя подкрепить конкретными и важными показателями: где имеются такие торфы и их запасы.

Так, геохимические и климатические особенности Западной Сибири, несомненно, находят отражение в особенностях состава и структуры органического вещества $(\mathrm{OB})$ западносибирских торфов. Выделен ряд видов торфа, не встречающихся на европейской территории России: согровый, лиственичный, пихтовый, осоково-злаковый, сосново-осоковый и др. [4, 5]. Однако исследования состава органического веще-

Инишева Лидия Ивановна - профессор кафедры биологии растений и биохимии, доктор сельскохозяйственных наук, член-корреспондент РАН, e-mail: inisheva@ mail.ru Маслов Станислав Григорьевич - доцент, кандидат технических наук, e-mail: maslovSG@ tpu.ru ства (OB) торфов малочисленны [6-9], выполнены с использованием разных методов анализа и не всегда могут быть сравнимы. Поэтому целью данной работы было изучение фракционногруппового состава ОВ торфов разного генезиса.

\footnotetext{
* Автор, с которым следует вести переписку.
} 


\section{Объекты и методы исследования}

Исследования проводились с торфами Томской области, представительными для ЗападноСибирского региона [10]. В пределах таежной и подтаежной областей были проведены экспедиционные исследования и отобраны образцы торфов в количестве четырех тысяч, относящихся по ботаническому составу к 55 видам. В дальнейшем для характеристики состава ОВ торфов были выбраны 140 образцов, относящихся к 12 видам, включая торфы низинного типа (древесный, древесно-осоковый и древеснотравяной, осоковый, травяной, осоково-гипновый, гипновый) и верхового типа (фускум, комплексный, сфагновый мочажинный, пушицево-сфагновый, шейхцериевый). Каждый вид торфа по ботаническому составу представлен выборкой из 6-19 образцов. В образцах определяли ботанический состав и степень разложения [ГОСТ 28245.2-89], зольность [ГОСТ 11306-83], фракционно-групповой состав углерода по В.В. Пономаревой и Т.А. Николаевой [11]. Все лабораторные исследования проводились в Испытательной лаборатории Томского государственного педагогического университета (№ POCC RU.0001.516054).

Статистическая обработка экспериментальных данных была выполнена с помощью пакетов статистических программ STATISTICA 6. Остановимся подробнее на обосновании выбора метода фракционирования ОВ торфа.

Существует значительное разнообразие методик изучения группового состава ОВ торфа, различающихся, прежде всего, последовательностью выделения отдельных групп ОВ, а также составом и концентрацией применяемых растворителей. Традиционным методом, широко использующимся при оценке качества торфа как сырья химической промышленности, является метод Инсторфа [12]. Однако в процессе анализа происходят значительные изменения состава и структуры органических соединений торфа. Особенно сильным изменениям подвергаются гуминовые вещества: происходит их частичный гидролиз, сопровождающийся «искусственной гумификацией» веществ неспецифической природы. За счет этого содержание негидролизуемого остатка существенно сокращается.

При изучении состава ОВ торфов и торфяных почв широкое распространение получил метод В.В. Пономаревой и Т.А. Николаевой [11], позволяющий выделить групповые составляющие в наименее измененном виде и дополнительно провести фракционирование гуминовых кислот. При этом выделяют три фракции гуминовых и 4 фракции фульвокислот, различающихся строением и характеризующих особенности гуминового комплекса торфа [13].

\section{Обсуждение результатов}

В исследуемых торфах липиды в среднем составляют 8,4\%, гумусовые кислоты - 38,1\%, гидроли-

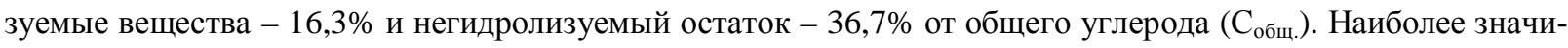
тельной по количеству и наиболее интересной с позиций биохимической устойчивости торфа является группа гумусовых кислот, представленная гуминовыми кислотами (ГК) и фульвокислотами (ФК). Рассмотрим характеристику этой группы веществ.

Общее содержание ГК в исследуемых торфах изменяется от 5,2 до 41,3\% от С общ. (табл. 1). Низинный торф содержит ГК в среднем 24,4\% с пределами колебаний 5,7-41,3\%, верховой - 16,5\% с пределами 5,2-31,8\%. Степень варьирования данного признака, оцененная по коэффициентам вариации, составляет 22$36 \%$ для торфов низинного типа и 28-52\% - для торфов верхового типа. Низкое содержание ГК (5-7\%) встречается как среди торфов верхового, так и низинного типа, наиболее характерно для травяно-моховых и моховых групп обоих типов. Наибольшее содержание ГК прослеживается в низинной древесно-травяной и травяной группе торфа, в которых средняя степень разложения достигает 26-31\%. Особенно высоким содержанием ГК по средним значениям выделяются торфа низинной травяной группы. Из этой закономерности выпадает осоковый вид торфа, в котором при достаточно высокой степени разложения $(27,5 \%)$ среднее содержание ГК значительно ниже среднего значения для травяной группы и не превышает $24 \%$ от Собщ. Повидимому, доля веществ, из которых в дальнейшем образуются ГК, в составе растительных остатков осоки ниже, чем в других видах торфов травяной группы. Можно предположить, что условия среды, при которых происходит образование осокового торфа из остатков осоки, способствуют накоплению веществ неспецифической природы, в результате чего степень разложения возрастает, но это не способствуют гумификации.

Относительно низкое содержание ГК при высокой степени разложения, отмечаемое для осокового и древесного видов торфа, свидетельствует о том, что степень разложения не всегда адекватно отражает уровень гумификации торфа. Для торфов низинной травяно-моховой и моховой групп характерно невысо- 
кое содержание ГК - в среднем 19,9-21,1\%, что, очевидно, обусловлено влиянием моховых торфообразователей. На основании вышеизложенного можно предположить, что в низинном типе торфа общее содержание ГК в большей степени определяется ботаническим составом, чем степенью разложения торфа. Общее содержание ГК в торфах низинного типа возрастает в ряду: травяно-моховая группа - моховая группа - древесная группа - древесно-травяная - травяная группа.

Верховой торф содержит ГК значительно меньше, чем низинный, при этом четко выражена прямая связь со степенью разложения. Особенно выделяется шейхцериевый торф, где среднее содержание ГК достигает $21,1 \%$ от $\mathrm{C}_{\text {общ. }}$ приближаясь к данным для низинных торфов. Предельное содержание ГК в торфах верховой травяной группы достигает 30,2\% (при степени разложения 35\%). Как и в низинных торфах, наибольшее среднее содержание ГК отмечается в травяной группе, наименьшее - в верховой моховой группе торфа $(14,0 \%)$.

Представляет интерес изучение особенностей распределения отдельных фракций ГК в зависимости от ботанического состава торфа. Первая фракция ГК (ГК1), выделяемая 0,1 н щелочью на холоде, соответствует содержанию свободных ГК в торфе. Эта фракция является наиболее окисленной, менее полидисперсной, содержит большое количество кислых функциональных групп, сильнее насыщена минеральными элементами и более гидрофильна. Содержание свободных гуминовых кислот в торфах изменяется от 1,8 до 23,3\% (табл. 1). Низинный торф, как правило, содержит больше свободных ГК, чем верховой (за исключением верхового шейхцериевого вида), в то время как различия по содержанию этой фракции в зависимости от типа торфа выражены значительно меньше, чем по общему содержанию ГК. Их экстремальные содер-

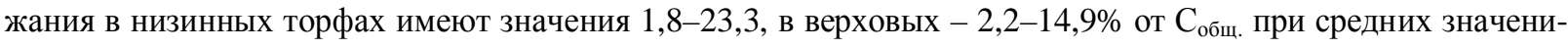
ях соответственно 4,3-9,3 и 5,5-9,7\% от С общ. То есть по средним значениям ГК1 торфа разных типов очень близки, при этом экстремальные значения различаются.

На основании полученных результатов можно констатировать, что по содержанию ГК1 торфа одноименных ботанических групп разных типов торфа различаются в меньшей степени, чем торфа разного ботанического состава одного типа. Эти результаты свидетельствуют о том, что накопление данной фракции ГК не связано с трофностью среды, при которой происходит образование торфа, а обусловлены иными причинами, например, исходным составом растительных остатков или особенностями водного режима болотного фитоценоза, отлагающего данный торф.

Особый интерес представляет изучение содержания ГК1 в зависимости от степени разложения торфа. В связи с этим нами вся совокупность данных была разбита на классы по степени разложения. При определении границ классов мы исходили из точности метода определения степени разложения и равномерности распределения числа наблюдений по классам. Для торфа верхового типа было выделено 4 класса (степень разложения - до 10\%; 10-15\%; 15-25\%; 25-35\%); для торфа низинного типа - 5 классов (степень разложения - до 20\%; 20-25\%; 25-30\%; 30-45\%; более 45\%). На основании полученных данных (табл. 2) можно констатировать увеличение содержания свободных ГК при возрастании степени разложения в пределах 5-30\% как для верхового, так и для низинного типа торфа. При степени разложения более $30 \%$ эта закономерность нарушается. Можно предположить, что уровень деструкции исходного органического вещества, определяемый степенью разложения 30\%, является границей, за которой прекращается накопление свободных ГК. Однако данное положение правомерно только для торфов низинного типа. Содержание ГК1 в верховых торфах закономерно возрастает на всем интервале изменения степени разложения и полностью соответствует уровню деструкции исходного ОВ.

Вторая фракция ГК (ГК2) связана с кальцием и соответствует содержанию «черных» или «серых» ГК. В торфах содержание этой фракции обычно низкое. Для нормальнозольных торфов присутствие ГК2 нехарактерно. По нашим данным, повышенное содержание ГК2 в торфах можно считать признаком вторичной зольности. Верховой тип торфа содержит ГК 2 не более $2,3 \%$ от Собщ. (см табл. 1). В низинном типе максимум ГК2 достигает 10,5\% и встречается в древесной и древесно-травяной группах, которые имеют максимальную степень разложения и характерны для торфяных месторождений пойменного залегания. Анализ полученных нами средних значений в торфах разных ботанических групп выявил закономерное снижение содержания ГК2 в ряду от низинной древесной группы к верховой моховой. Рассмотрим зависимость средних содержаний фракций ГК2 в торфах, сгруппированных по зольности (табл. 3). 
Таблица 1. Содержание отдельных фракций гумусовых веществ торфов, \% от общего углерода $\left(\mathrm{C}_{\text {общ. }}\right)$

\begin{tabular}{|c|c|c|c|c|c|c|c|c|c|}
\hline \multirow{2}{*}{$\begin{array}{l}\text { Ботанический } \\
\quad \text { состав }\end{array}$} & \multirow{2}{*}{ 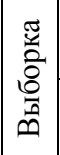 } & \multicolumn{2}{|c|}{$\begin{array}{c}\text { Сумма гуминовых } \\
\text { кислот }\end{array}$} & \multicolumn{2}{|c|}{\begin{tabular}{|c} 
Гуминовые кислоты - \\
$1-я$ фракция
\end{tabular}} & \multicolumn{2}{|c|}{$\begin{array}{c}\text { Гуминовые кислоты - } \\
\text { 2-я фракция } \\
\end{array}$} & \multicolumn{2}{|c|}{ Сумма фульвокислот } \\
\hline & & $\frac{\text { экстремумы }}{\text { среднее }}$ & дисперсия & $\frac{\text { экстремумы }}{\text { среднее }}$ & дисперсия & $\frac{\text { экстремумы }}{\text { среднее }}$ & дисперсия & $\frac{\text { экстремумы }}{\text { среднее }}$ & дисперсия \\
\hline \multicolumn{10}{|c|}{ Тип низинный } \\
\hline $\begin{array}{l}\text { Группа } \\
\text { древесная }\end{array}$ & 18 & $\frac{17,8-34,4}{25,0}$ & 5,5 & $\frac{2,7-12,0}{5,6}$ & 0,4 & $\frac{0,7-10,5}{5,2}$ & 6.8 & $\frac{10,4-29,1}{18,9}$ & 4,4 \\
\hline $\begin{array}{l}\text { Группа древес- } \\
\text { но-травяная }\end{array}$ & 19 & $\frac{13 \cdot 0-37,8}{26,3}$ & 7,1 & $\frac{3,3-21,7}{8,1}$ & 0,6 & $\frac{\mathrm{cл-}-10,5}{3,7}$ & 8.8 & $\frac{10,7-30,8}{17,0}$ & 5,1 \\
\hline $\begin{array}{l}\text { Вид древесно- } \\
\text { травяной }\end{array}$ & 14 & $\ldots$ & & $\frac{3,3-21,7}{9,3}$ & 0,6 & $\begin{array}{c}\text { сл-9,2 } \\
3,3\end{array}$ & 7.0 & $\begin{array}{c}11,9-24,0 \\
16,5\end{array}$ & 4,1 \\
\hline Группа травяная & 35 & $\frac{7,0-41,3}{26,2}$ & 6,7 & $\ldots$ & & $\begin{array}{c}\text { сл-7,0 } \\
2,3\end{array}$ & 4.3 & $\begin{array}{c}8,3-28,8 \\
17,6\end{array}$ & 4,9 \\
\hline Вид травяной & 19 & $\frac{19,1-41,3}{28,1}$ & 6,1 & $\frac{3,8-9,1}{5,6}$ & 0,3 & $\frac{\text { сл- } 6,2}{2,9}$ & 5.4 & $\frac{12,3-28,8}{18,0}$ & 5,5 \\
\hline Вид осоковый & 16 & $\frac{7,0-32,4}{24,0}$ & 6,8 & $\frac{3,3-23,3}{9,9}$ & 0,7 & $\frac{\text { сл-7,0 }}{1,8}$ & 3.9 & $\frac{8,3-25,0}{17,2}$ & 4,5 \\
\hline $\begin{array}{l}\text { Группа травяно- } \\
\text { моховая }\end{array}$ & 14 & $\frac{5,7-31,5}{18,9}$ & 7,2 & $\frac{2,5-9,0}{5,2}$ & 0,4 & $\frac{\text { сл-6,9 }}{1,7}$ & 4.2 & $\frac{8,3-21,0}{14,8}$ & 4,3 \\
\hline $\begin{array}{l}\text { Группа моховая } \\
\text { (гипновый) }\end{array}$ & 14 & $\frac{9,9-35,6}{21,2}$ & 21,2 & $\frac{1,8-8,4}{4,3}$ & 0,4 & $\frac{\mathrm{cл}-5,1}{1,5}$ & 2.7 & $\frac{7,5-19,7}{14,4}$ & 3,6 \\
\hline \multicolumn{10}{|c|}{ Тип верховой } \\
\hline $\begin{array}{l}\text { Вид } \\
\text { шейхцериевый }\end{array}$ & 4 & $\frac{13,3-30,2}{21,1}$ & 7,2 & $\frac{3,9-14,9}{9,7}$ & 0,5 & $\ldots$ & & $\frac{11,0-18,9}{14,7}$ & 3,2 \\
\hline $\begin{array}{l}\text { Вид пушицево- } \\
\text { сфагновый }\end{array}$ & 12 & $\frac{7,4-31,8}{16,8}$ & 8,7 & $\frac{2,8-12,6}{6,6}$ & 0,5 & $\frac{\mathrm{cл-}-2,3}{0,7}$ & 0.5 & $\frac{5,9-20,2}{11,6}$ & 3,5 \\
\hline $\begin{array}{l}\text { Группа травяно- } \\
\text { моховая }\end{array}$ & 14 & $\frac{7,4-31,8}{17,0}$ & 8,3 & $\frac{2,8-12,6}{6,6}$ & 0,5 & $\frac{\mathrm{cл}-2,3}{0,9}$ & 0.5 & $\frac{8,8-15,4}{11,4}$ & 2,4 \\
\hline Группа моховая & 19 & $\frac{5,2-32,1}{14,0}$ & 6,3 & $\frac{2,2-10,7}{5,5}$ & 0,4 & $\frac{\mathrm{cл}-1,4}{0,5}$ & 0.3 & $\frac{9,9-26,0}{13,5}$ & 3,7 \\
\hline Вид фускум & 6 & $\frac{5,2-13,9}{10,9}$ & 3,1 & $\frac{2,2-5,3}{4,1}$ & 0,3 & $\frac{\mathrm{cл}-1,4}{0,8}$ & 0.3 & $\frac{13,1-17,5}{15,2}$ & 1,4 \\
\hline $\begin{array}{l}\text { Вид } \\
\text { комплексный }\end{array}$ & 8 & $\frac{7,4-22,7}{15,4}$ & 5,7 & $\frac{3,4-10,7}{6,5}$ & 2,5 & $\frac{\mathrm{c} \Omega-1,3}{0,4}$ & 0.4 & $\frac{9,1-13,9}{11,6}$ & 1,9 \\
\hline
\end{tabular}

Примечание: сл - означает содержание компонента, близкое к нулю.

Таблица 2. Содержание свободных гуминовых кислот в торфах с разной степенью разложения, \% от общего углерода $\left(\mathrm{C}_{\text {обш. }}\right)$

\begin{tabular}{|c|c|c|c|c|c|}
\hline Степень разложения, \% & Выборка & Среднее & Минимум & Максимум & Дисперсия \\
\hline \multicolumn{6}{|c|}{ Низинные торфы } \\
\hline $12-20$ & 17 & 5,4 & 2,1 & 10,0 & 0,4 \\
\hline $20-25$ & 21 & 6,0 & 2,9 & 18,2 & 0,5 \\
\hline $25-30$ & 26 & 7,7 & 2,7 & 23,3 & 0,8 \\
\hline $30-45$ & 32 & 6,6 & 1,8 & 20,3 & 0,6 \\
\hline $45-55$ & 4 & 9,4 & 4,1 & 21,7 & 0,9 \\
\hline \multicolumn{6}{|c|}{ Верховые торфыл } \\
\hline $0-10$ & 8 & 4,5 & 2,2 & 8,7 & 0,5 \\
\hline $10-15$ & 13 & 5,4 & 2,8 & 10,7 & 0,5 \\
\hline $15-25$ & 10 & 7,4 & 3,5 & 14,9 & 0,4 \\
\hline $25-35$ & 9 & 10,7 & 3,9 & 19,4 & 0,5 \\
\hline
\end{tabular}

Таблица 3. Содержание второй фракции ГК в торфах с разной зольностью, \% от общего углерода $\left(\mathrm{C}_{\text {общ. }}\right)$

\begin{tabular}{c|c|c|c|c|c}
\hline Зольность, \% & Выборка & Среднее & Минимум & Максимум & Дисперсия \\
\hline $0,4-2,4$ & 28 & 0,6 & сл & 2,3 & 0,4 \\
$2,5-4,9$ & 18 & 0,6 & сл & 1,8 & 0,5 \\
$5,0-9,9$ & 19 & 0,7 & сл & 2,3 & 0,8 \\
$10,0-14,9$ & 22 & 3,6 & сл & 10,5 & 0,6 \\
$15,0-34,9$ & 36 & 3,8 & сл & 10,5 & 3,3 \\
Более 34,9 & 17 & 3,1 & сл & 10,2 & 3 \\
\hline
\end{tabular}




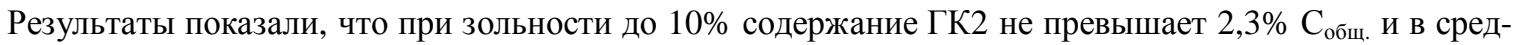
нем составляет 0,6-0,7\%, а при зольности более $10 \%$ - резко возрастает до 3,0-3,7\% С общ. Вместе с тем постепенного увеличения содержания ГК2 с увеличением зольности не наблюдается. Зольность $10 \%$ служит границей, ниже которой наиболее вероятны нормальная (первичная) зольность торфа и низкие содержания ГК2. Торф является нормально зольным, т.е. в его формировании не участвуют грунтовые, пойменные или атмосферные минеральные вещества, при зольности менее 12\% [14]. Следовательно, повышенное содержание ГК2 в торфах можно считать признаком влияния вторичной зольности. Для нормально зольных торфов присутствие ГК2 нехарактерно. Известно, что зольность торфа является косвенным показателем трофности среды, при которой происходит торфообразование. По-видимому, фракцию ГК2, распределение которой в целом соответствует распределению зольности, с некоторым допущением можно считать параметром трофности болотного биогеоценоза. А уровень трофности, в свою очередь, определяет тот или иной состав растительных группировок болотного биогеоценоза и, соответственно, химический состав отлагаемого ими торфа. Отсюда следует, что геохимические условия торфообразования оказывают определенное влияние на содержание ГК2 в торфах.

Третью фракцию ГК (ГКЗ) Т.Т. Ефремова [9] характеризует как восстановленную форму бурых ГК начальной стадии гумусообразования. По-видимому, исходя из соображений некоторой искусственности ГК3 в торфах, многие исследователи [15-17] рассматривают как общий уровень содержания ГК в торфах сумму первой и второй фракций ГК и не определяют содержание ГКЗ. Во всех исследуемых торфах в составе ГК преобладает третья фракция. Она составляет около 60\% от суммы ГК и определяет основные закономерности изменений в общем содержании ГК.

Существенная часть гумусовых кислот торфов представлена фульвокислотами (ФК) - 5,9-30,8\% от Собщ. Обнаруженные в последнее время уникальные свойства ФК (высокие поглотительная и комплексообразующая способность) делают перспективным их практическое использование. Среднее содержание ФК в верховых торфах составляет 13,7\% Собщ., в низинных - 16,9\%. Среднее содержание ФК по группам торфа изменяется также незначительно, от 11,6 до 18,9\% Собщ. В целом, более высоким содержанием ФК характеризуются низинные группы торфа, однако это различие несущественно. По содержанию отдельных фракций ФК торф разного ботанического состава также не имеет явных различий. Уровень фракций ФК всегда ниже уровня соответствующих фракций ГК.

\section{Bbыводbl}

Вышеизложенное позволяет отметить особенности содержания ГК и их фракций в западносибирских торфах. Для торфов верхового типа характерно невысокое содержание ГК. Особое место занимает верховой шейхцериевый торф (с максимальной для типа степенью разложения), фракционный состав которого существенно отличается от торфов верхового типа повышенным содержанием ГК. Торф верховой моховой группы характеризуется самым низким содержанием ГК. Торф верховой травяно-моховой группы по составу ГК занимает промежуточное положение.

Фракционный состав гумусовых кислот (ГК и ФК) на уровне групп торфа связи с ботаническим составом не обнаруживает и может рассматриваться в аспекте специфики формирования системы гумусовых веществ при торфообразовании в болотных экосистемах.

Исследование фракционно-группового состава ОВ торфов разного ботанического состава методом Пономаревой-Николаевой позволило выявить следующие закономерности, связанные с генезисом. Степень разложения нельзя считать показателем, отражающим уровень гумификации торфа и содержание в нем ГК без учета его ботанического состава. Общее содержание ГК в торфах низинного типа возрастает в ряду травяно-моховая группа - моховая группа - древесная группа - древесно-травяная, травяная группа. По содержанию ГК1 торфа одноименных ботанических групп разных типов торфа различаются в меньшей степени, чем торфа разного ботанического состава одного типа. На содержание ГК2 в торфах оказывают влияние геохимические условия торфообразования. Повышенное содержание ГК2 в торфах предлагается считать признаком вторичной зольности. Во всех исследуемых торфах в составе ГК преобладает ГКЗ. Эта фракция составляет около 60\% от суммы ГК и определяет основные закономерности изменений в общем содержании ГК.

Исследования показали, как важно иметь кадастр торфов с данными по ботаническому составу, физико-химическим показателям, групповому и фракционно-групповому составу органического вещества торфов и в особенности - его гуминовой составляющей. Это позволит выбрать виды или группу торфов и его сырьевую базу для более детальных и сложных последующих исследований направленного действия, что позволит сэкономить время и финансы. 


\section{Список литературы}

1. Ефанов М.В., Новоженов В.А., Франкивский В.Н. Окислительный аммонолиз торфа в условиях кавитационной обработки // Химия растительного сырья. 2010. №1. С. 165-169.

2. Инишева Л.И., Юдина Н.А., Соколова И.В., Ларина Г.В. Особенности гуминовых кислот торфов Западной Сибири // Химия растительного сырья. 2013. №4. С. 179-185.

3. Зыкова М.В., Белоусов М.В., Гурьев А.М., Ахмеджанов Р.Р., Юсубов М.С. Стандартизация гуминовых кислот низинного древесно-травяного вида торфа Томской области // Химико-фармацевтический журнал. Т. 47, №12. C. $53-56$.

4. Марков В.В., Оленин А.С., Оспенникова Л.А., Скобеева Е.И., Хорошев П.И. Торфяные ресурсы мира. М., 1988. $384 \mathrm{c}$.

5. Классификация растительного покрова и видов торфа Центральной части Западной Сибири / Мингео РСФСР: трест «Геолторфразведка». М., 1975. 150 с.

6. Ефимов В.Н. Торфяные почвы. М., 1980. 120 с.

7. Широких П.С. Органическое вещество и соединения азота внизинных торфяных почвах с различным ботаническим составом // Сибирский вестник сельско-хозяйственной науки. 1981. №1. С. 6-20.

8. Бамбалов Н.Н. Минерализация и трансформация органического вещества торфяных почв при их сельскохозяйственном использовании (на примере торфяных почв Белоруссии): дисс. ... д-ра с.-х. наук. Минск, 1983. 497 с.

9. Ефремова Т.Т. Гумус и структурообразование в лесных торфяных почвах Западной Сибири: автореф. дисс. ... д-ра биол. наук. Новосибирск, 1990. 48 с.

10. Львов Ю.А. Болотные ресурсы // Природные ресурсы Томской области. Новосибирск, 1991. С. 67-82.

11. Пономарева В.В., Николаева Т.А. Методы изучения органического вещества в торфо-болотных почвах // Почвоведение. 1961. №5. С. 88-95.

12. Лиштван И.И., Базин Е.Т., Гамаюнов Н.И., Терентьев А.А. Физика и химия торфа: учеб. пособие для вузов. M., 1989. $304 \mathrm{c}$.

13. Переверзев В.Н. Биохимия гумуса и азота почв Кольского полуострова. Л., 1987. 303 с.

14. Тюремнов С.Н. Торфяные месторождения и их разведка. М., 1976. 488 с.

15. Бухман В.А. К познанию группового и фракционного состава органического вещества торфяных почв Карелии // Труды Карельского филиала АН СССР. Л., 1957. С. 108-114.

16. Ефимов В.Н. Торфяные почвы. М., 1980. 120 с.

17. Широких П.С. Органическое вещество и соединения азота в низинных торфяных почвах с различным ботаническим составом // Сибирский вестник сельско-хозяйственной науки. 1981. №1. С. 16-20.

Поступило в редакцию 5 марта 2015 г.

После переработки 5 мая 2015 г. 


\section{PEATS}

Inisheva L.I. ${ }^{*}$, Maslov S.G. ${ }^{2}$ TO QUESTION ABOUT CHARACTERISTICS OF HUMIC ACIDS OF SIBERIAN

${ }^{I}$ Tomsk State Pedagogical University, Kievskaia st., 60, Tomsk, 634061 (Russia), e-mail: inisheva@mail.ru

${ }^{2}$ Institute of Natural Resources of Tomsk Polytechnic University, Lenina st., 30, Tomsk, 634050 (Russia),

e-mail: maslovSG@tpu.ru

One of the natural resources for ecological agriculture, medicine and chemical industry is a peat. However investigation the composition of peat organic matter $(\mathrm{OM})$ with provision of botanical composition are small in number, and Its are executed with using the different methods of the analysis and not always can be comparable. So purpose of this work was an investigation of factious-group composition of OM of different genesis peat.

Within taiga and under taiga zones (Tomsk region) is selected 140 samples of peats. Each type of the peats on botanical composition is presented by sample from 6-19 samples. There is organized analysis of the composition of organic substances westsiberian peats by method of Ponomarevoy-Nikolaevoy. This method was made more detail study of factious of Humic Acids.

So, the total contents HA in peats of the low-mire type increases: grass moss group - moss group - wood group wood-grass, grass group. Geochemical conditions of peat formation influences on contents HA2 in peats. The high contents HA2 in peats is offered consider the sign of secondary ash content. In all peats in composition of HA dominates HA3. This forms are near $60 \%$ from total HA and defines the main regularities of the changes in total contents of HA.

Keywords: peat, West Siberia, organic substances, organic matter, humic acids, peat formation, ash content.

\section{References}

1. Efanov M.V., Novozhenov V.A., Frankivskii V.N. Khimiia rastitel'nogo syria, 2010, no. 1, pp. 165-169. (in Russ.).

2. Inisheva L.I., Iudina N.A., Sokolova I.V., Larina G.V. Khimiia rastitel'nogo syr'ia, 2013, no. 4, pp. 179-185. (in Russ.).

3. Zykova M.V., Belousov M.V., Gur'ev A.M., Akhmedzhanov R.R., Iusubov M.S. Khimiko-farmatsevticheskii zhurnal, 2013, vol. 47, no. 12, pp. 53-56. (in Russ.).

4. Markov V.V., Olenin A.S., Ospennikova L.A., Skobeeva E.I., Khoroshev P.I. Torfianye resursy mira. [Peat resources of the world]. Moscow, 1988, 384 p. (in Russ.).

5. Klassifikatsiia rastitel'nogo pokrova $i$ vidov torfa Tsentral'noi chasti Zapadnoi Sibiri. [Classification of vegetation types of peat and the central part of Western Siberia]. Moscow, 1975, 150 p. (in Russ.).

6. Efimov V.N. Torfianye pochvy. [Peat soil]. Moscow, 1980, 120 p. (in Russ.).

7. Shirokikh P.S. Sibirskii vestnik sel'sko-khoziaistvennoi nauki, 1981, no. 1, pp. 6-20. (in Russ.).

8. Bambalov N.N. Mineralizatsiia i transformatsiia organicheskogo veshchestva torfianykh pochv pri ikh sel'skokhoziaistvennom ispol'zovanii (na primere torfianykh pochv Belorussii): dis. ... d-ra s.-kh. nauk. [Mineralization and transformation of organic matter in peat soils at their agricultural use (for example, peat soils in Belarus): the dissertation doktorara Agricultural Sciences]. Minsk, 1983, 497 p. (in Russ.).

9. Efremova T.T. Gumus i strukturoobrazovanie v lesnykh torfianykh pochvakh Zapadnoi Sibiri: avtoref. dis. ... d-ra biol. nauk. [Humus and structure formation in forest peat soils of Western Siberia: the Dissertation of the doctor of biological sciences]. Novosibirsk, 1990, 48 p. (in Russ.).

10. L'vov Iu.A. Prirodnye resursy Tomskom oblasti. [Natural resources Tomsk region]. Novosibirsk, 1991, pp. 67-82. (in Russ.).

11. Ponomareva V.V., Nikolaeva T.A. Pochvovedenie, 1961, no. 5, pp. 88-95. (in Russ.).

12. Lishtvan I.I., Bazin E.T., Gamaiunov N.I., Terent'ev A.A. Fizika i khimiia torfa. [Physics and chemistry of peat]. Moscow, 1989, 304 p. (in Russ.).

13. Pereverzev V.N. Biokhimiia gumusa i azota pochv Kol'skogo poluostrova. [Biochemistry humus and nitrogen soils of the Kola Peninsula]. Leningrad, 1987, 303 p. (in Russ.).

14. Tiuremnov S.N. Torfianye mestorozhdeniia $i$ ikh razvedka. [Peat deposits and their exploration]. Moscow, 1976, 488 p. (in Russ.).

15. Bukhman V.A. Trudy Karel'skogo filiala AN SSSR. [Proceedings of the Karelian branch of the Academy of Sciences of the USSR]. Leningrad, 1957, pp. 108-114. (in Russ.).

16. Efimov V.N. Torfianye pochvy. [Peat soil]. Moscow, 1980, 120 p. (in Russ.).

17. Shirokikh P.S. Sibirskii vestnik sel'sko-khoziaistvennoi nauki, 1981, no. 1, pp. 16-20. (in Russ.).

Received March 5, 2015

Revised May 5, 2015

\footnotetext{
* Corresponding author.
} 
